\title{
Associations of the Burden of Coal Abandoned Mine Lands with Three Dimensions of Community Context in Pennsylvania
}

\author{
Ann Y. Liu, ${ }^{1}$ Frank C. Curriero, ${ }^{1,2}$ Thomas A. Glass, ${ }^{3}$ \\ Walter F. Stewart, ${ }^{4}$ and Brian S. Schwartz ${ }^{1,3,4}$ \\ ${ }^{1}$ Department of Environmental Health Sciences, Johns Hopkins Bloomberg School of Public Health, Baltimore, MD 21205, USA \\ ${ }^{2}$ Department of Biostatistics, Johns Hopkins Bloomberg School of Public Health, Baltimore, MD 21205, USA \\ ${ }^{3}$ Department of Epidemiology, Johns Hopkins Bloomberg School of Public Health, Baltimore, MD 21205, USA \\ ${ }^{4}$ Center for Health Research, Geisinger Health System, Danville, PA 17822, USA \\ Correspondence should be addressed to Brian S. Schwartz, bschwart@jhsph.edu
}

Received 13 February 2012; Accepted 29 February 2012

Academic Editors: H. B. Bueno-de-Mesquita and I. Szadkowska-Stanczyk

Copyright ( $) 2012$ Ann Y. Liu et al. This is an open access article distributed under the Creative Commons Attribution License, which permits unrestricted use, distribution, and reproduction in any medium, provided the original work is properly cited.

\begin{abstract}
Background. Pennsylvania, with thousands of abandoned coal mines and miles of streams polluted with acid mine drainage, has the largest domestic coal mining burden contributing to deterioration of communities. Objectives. To evaluate contextual aspects by examining associations between coal abandoned mine lands (AML) and community measures of socioeconomic deprivation, social disorganization, and physical disorder. Methods. AML exposure data from the Reclaimed Abandoned Mine Land Inventory System were used to create density, diversity, accessibility, and clustering metrics. The three community context outcome measures were comprised of 14 census variables. In community-level analyses, 10 AML variables were evaluated separately with each dimension of community context, adjusting for covariates, in communities with and without abandoned mines. Results. We observed consistent associations between higher AML burden and worse socioeconomic deprivation, negative relations with social disorganization, but no statistically significant associations with physical disorder. Six of 10 AML variables were associated with socioeconomic deprivation, many consistently exhibiting exposure-effect patterns of worse deprivation with greater AML. Conclusions. Higher AML was associated with higher socioeconomic deprivation. These results can help prioritize the use of Surface Mining Control and Reclamation Act funds and inform decisions regarding Marcellus shale drilling to prevent analogous environmental degradation and public health impacts.
\end{abstract}

\section{Introduction}

Pennsylvania has long been a witness to the negative impacts of energy fuel extraction industries. The quest for fossil fuels began in 1761 with coal mining, followed by petroleum drilling in 1859, and now a growing and controversial interest in natural gas drilling from shale [1]. An extensive history of coal mining has left the state with the worst legacy of scarred and contaminated landscapes in the USA $[2,3]$. These vast expanses of coal abandoned mine lands (AMLs) encompass terrestrial or aquatic sites of ore or mineral extraction, beneficiation, or processing, and waste deposit locations [2]. Although the Surface Mining Control and Reclamation Act (SMCRA) of 1977 established a fund to reclaim coal mines abandoned prior to the statute, relatively little scientific evidence was used for priority classifications of sites based on public health protection [4].

The settings in which people live and work influence health $[5,6]$. Characteristics of communities that are external to the individual have important implications for health [7, 8]. For example, communities that lack in material and social resources have a higher prevalence of cardiovascular risk factors and diseases [9-12], higher rates of chronic kidney diseases $[13,14]$, poor maternal and infant health [15, 16], and poor mental health outcomes [17-19], even after controlling for individual socioeconomic, lifestyle, and clinical factors. Communities characterized by visible environmental degradation from past coal mining activities may present a wide spectrum of external physical and psychosocial hazards that may compromise physical safety and expose 
persons to unattractive and contaminated landscapes that, encountered on a daily basis, could lead to impacts on health by modifying health-related behaviors or via other mechanisms $[20,21]$. There are no prior studies of the burden of AML left behind by the coal industry and influences on community context, but current coal production is associated with increased community mortality from lung cancer, cardiovascular, respiratory, and renal disease, and hypertension [22-25].

We hypothesized that communities with a greater burden of AML would have greater socioeconomic deprivation, social disorganization, and physical disorder, three measures of community context that have been linked to adverse individuallevel health outcomes [26-32]. The findings from such research could provide useful, public health-relevant guidance for reclamation strategies with coal AML and regulation of current drilling for natural gas deposits in shale.

\section{Methods}

In this ecologic study, we examined 10 AML measures using Reclaimed Abandoned Mine Land Inventory System (RAMLIS) data in relation to 2000 Census-based measures of socioeconomic deprivation, social disorganization, and physical disorder across 1283 Pennsylvania communities. We used multiple linear and logistic regression to examine ecologic relations. We also conducted sensitivity analyses to evaluate whether reclamation status and spatial dependence influenced associations. ArcGIS 9 and ESRI ArcMap version 9.2 (Redlands, CA) were used to georeference data from all sources into one spatially linked database to create community context outcomes, AML exposure metrics, and maps.

2.1. Definition of Communities. Because our study area was comprised of rural and urban areas, small towns, and villages, no single geography was ideal. Given this diversity, we implemented a mixed definition of community by combining minor civil divisions (MCDs) and census tracts (CTs), both of which honor county boundaries. MCDs are primary governmental divisions of a county categorized predominantly as townships, boroughs, or cities. MCD boundaries are too large and heterogeneous in cities and include dozens of urban CTs. In urban areas, CTs are small, relatively permanent statistical subdivisions that average about 4000 people, but rural CTs can be too large and heterogeneous $(>100$ miles $^{2}$ ) and include many small towns. We chose a mixed definition of community that used the MCD boundaries for townships and boroughs, given their sociological validity, and used census tract boundaries in cities to capitalize on the greater spatial resolution for more densely populated areas.

2.2. Study Area. The geographic study area included all 943 communities (i.e., township, borough, or census tract) that had at least one abandoned mine and a sample of 340 "control" communities that had no abandoned mines. To reduce residual influences from the AML communities, we defined the non-AML control communities as those sharing a border with a community that was also free of AML but immediately adjacent to an AML community, (Figure 1). We used a sample of non-AML communities to exclude such areas as the urban region of Philadelphia, which may be less comparable to communities with AML on a variety of factors relevant to health.

2.3. Data Sources. AML variables were derived from the RAMLIS based on national, state, and local data [3]. RAMLIS includes information on approximately 30 mine features for abandoned and reclaimed (i.e., those that had at least one feature with a completed remediation activity) coal mines. Each feature was characterized by up to six dimensions (i.e., area, length, volume, height, flow, and count), but we focused on the more comprehensive count and area dimensions to create standard measures of place [33-35]. For the dimensions of community context and key covariates of interest, data were abstracted from the USA Census 2000 shortform and long-form questionnaires, summary files 1 and 3 , respectively. U.S. Census 2000 TIGER/Line files were used for cartographic community boundaries.

2.4. Outcome Variables. From a combination of expert opinion and prior studies [30,36-40], we used standard methods to generate summary scores for three dimensions of community context. The measure of socioeconomic deprivation was a modified version of the Townsend index, originally developed to measure material deprivation in urban environments in Great Britain and commonly used in epidemiologic studies $[27,36]$. Because this study involved rural areas and small towns and boroughs that presented contrasting community landscapes, we developed and validated an alternative measure by replacing crowding and home ownership with indicators of low education, poverty, public assistance, and labor force nonparticipation. Socioeconomic deprivation and social disorganization were conceptualized as scales based on prior theory and operationalized as the sum of the z-scores of the appropriately transformed indicators. Our measurement model was tested using maximum likelihood factor analyses for each scale to ensure an adequate model fit to a single factor. Physical disorder was treated as an index [41] and modeled as an ordinal variable (low, medium, high).

2.5. Primary AML Exposure Variables. To ensure sufficient spatial variability across the overall geography, we used only the 11 mine features that had at least 500 occurrences across the state (i.e., dry strip mines, flooded strip mines, abandoned structure and equipment, high walls, open mine shafts, subsidence prone areas, vertical mine shafts, acid mine drainage discharges, refuse piles, spoil piles, and untreated discharges). We derived measures of density, diversity, accessibility, and clustering for total abandoned and reclaimed features, reclaimed features only, and abandoned features only. These were then reduced to 10 primary AML variables, which were selected because they were generally orthogonal and represented a priori hypotheses about how AML may influence community context.

Three density metrics were formulated along a priori dimensions that captured aspects of AML burden relevant to 


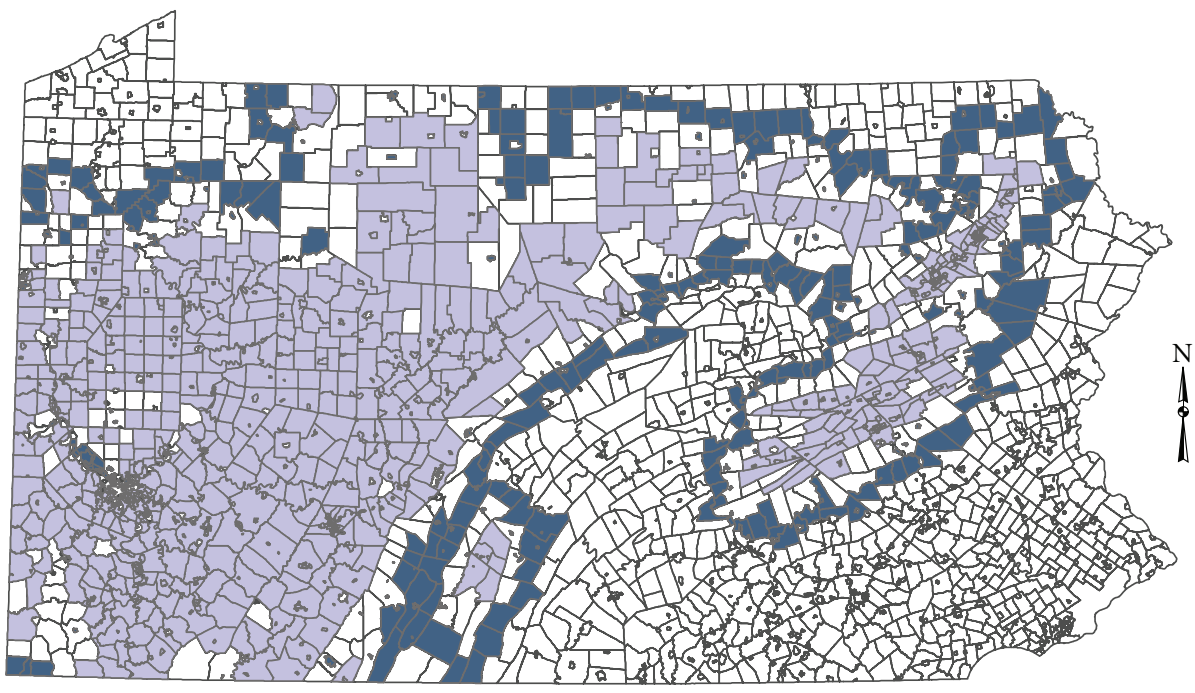

Communities with abandoned mines $(n=943)$

Communities without abandoned mines $(n=340)$

Figure 1: The geographic study area of Pennsylvania representing the 943 communities with at least one abandoned mine and the selected 340 control communities with no abandoned mines.
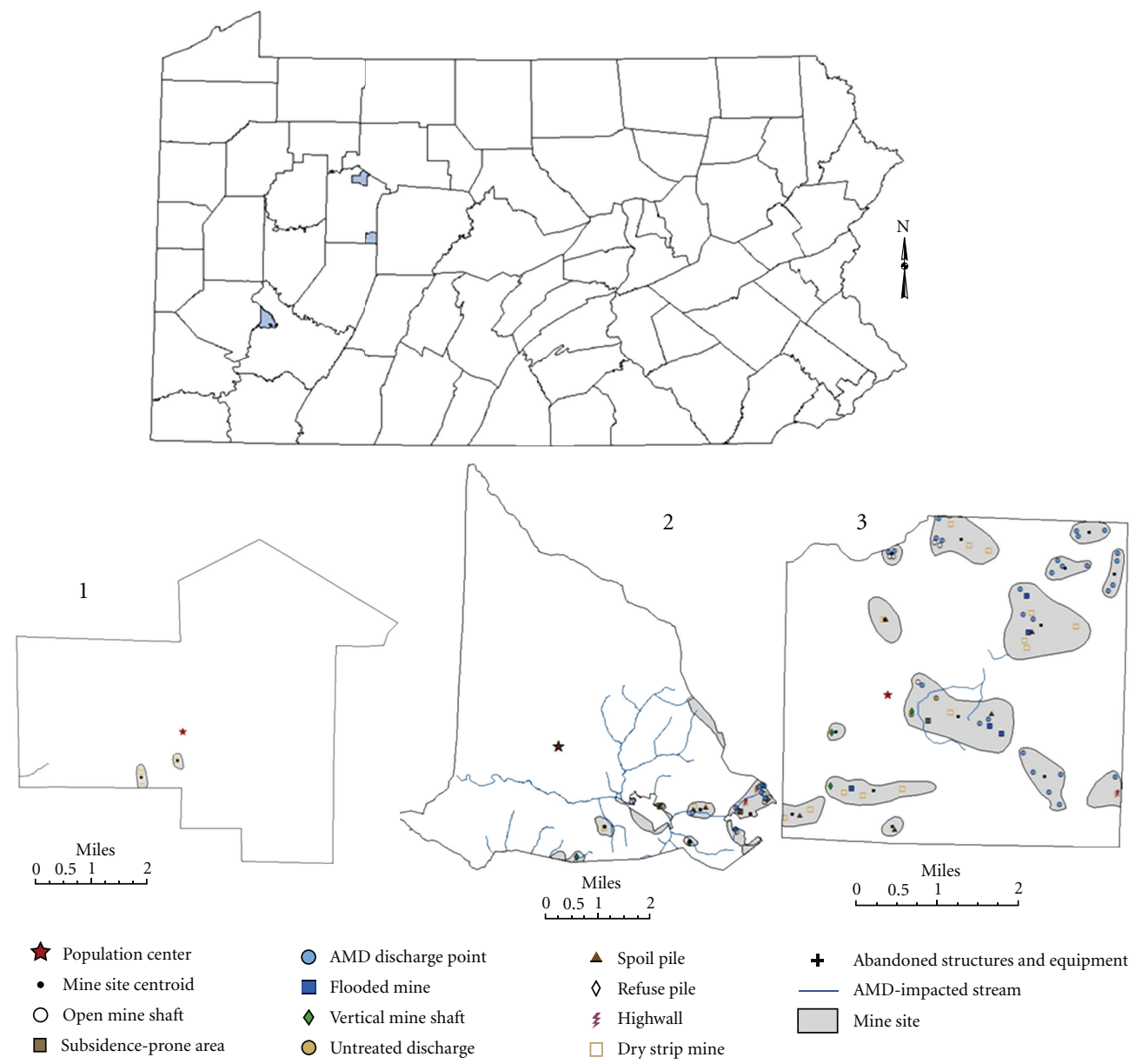

Figure 2: Example of three selected geographies in the study area representing low (Polk Township-1), moderate (Municipality of Murraysville Borrough-2), and high (Gaskill Township-3) burden of AML features in communities. 
health: (1) aesthetic quality referring to the attractiveness of landscapes; (2) physical hazards that have the potential to cause bodily harm; and (3) toxic contamination stemming from various sources within abandoned mines. The density of aesthetic quality features was calculated as the count of dry strip mines, flooded strip mines, and abandoned structures and equipment divided by the area of the community. The density of physical hazards used the count of high walls, open mine shafts, subsidence prone areas, and vertical mine shafts divided by the area. The density of toxic contamination features was calculated as the count of acid mine drainage discharges, refuse piles, spoil piles, and untreated discharges divided by the area.

Four additional density measures were created to fully characterize the burden of AML in communities and to evaluate SMCRA priority problems. The density of abandoned mine areas (total area of all abandoned mine sites within a community divided by area of community) and the density of acid mine drainage-impacted streams (total distance of affected streams within the community divided by community area) were included as easily interpreted, readily visualized, community-wide measures. SMCRA defines 17 AML problems as "high priority" that pose a threat to health, safety, and general welfare of people, so the density of SMCRA priority 2 and priority 3 areas was included to evaluate this scheme.

Three additional AML burden metrics were created. Diversity was measured as a count of the presence of the 11 mine features plus acid mine drainage-impacted streams. Accessibility characterized the "intensity of the possibility for interaction" between people and AML features [35]. A single metric was calculated as nearest neighbor Euclidean distances from the population center of each community to each of the 11 mine features, summing the z-score-transformed distances for each feature, then standardizing for direction so that larger values represented increased accessibility. Finally, the mean of the interpoint squared distances between mine centroids measured the extent of clustering of abandoned mines according to the formula: $\bar{d}^{2}=(2 / n(n-$ 1)) $\sum \sum\left[\left(x_{i}-x_{j}\right)^{2}+\left(y_{i}-y_{j}\right)^{2}\right]$, where $n$ is total abandoned mine centroids, $x$ is longitude of mine centroid, $y$ is latitude of mine centroid, $i$ is abandoned mine number $1, j$ is abandoned mine number 5536 [42]. Clustering was included because communities could have similar density measures but have widely dispersed or tightly clustered abandoned mines. We hypothesized that more tightly clustered mines were worse for community context. Clustering could not be calculated for 340 communities with no abandoned mines and mine features, 212 communities with no abandoned mine centroids, and 202 communities with one centroid. For the remaining 529 communities with two or more abandoned mines the calculated clustering metric was negated so that larger values, more highly clustered, represented greater AML burden.

The final 10 AML exposure variables used in the analysis were thus density of abandoned mine areas, aesthetic quality features, physical hazards, toxic contamination features, priority 2 features, and priority 3 features; clustering, accessibil- ity, diversity; and density of acid mine drainage-impacted streams. There was large variation in the measures across communities; Figure 2 shows AML features for three selected communities representing low, moderate, and high burden of AML.

2.6. Data Analysis. The goals of the analysis were to (1) evaluate main effect associations among AML burden variables and three dimensions of community context; and (2) conduct sensitivity analyses to assess reclamation status on these associations. All data analyses were at the community level and performed with SAS version 9.1 (Cary, NC).

For the main analyses, we used variables created from all reclaimed and unreclaimed features. Multiple linear regression was used for socioeconomic deprivation and social disorganization, while polytomous logistic regression was used for physical disorder, assuming a nonmonotonic relationship with exposure and a three-level outcome (low (0-50th percentile), medium (51st-90th percentile), and high ( $\geq 91$ st percentile)). Separate regressions were conducted for each AML exposure variable among the 943 AML communities. Three of the AML variables were modeled as continuous variables (accessibility, diversity, and density of acid mine drainage-impacted streams) and the others were modeled as categorical variables (reference group of zero values, with nonzero values frequency-divided into three or four groups). Unadjusted regressions for each AML exposure variable were then adjusted for potential confounders added one at a time, including population density (population per square mile), proportion male, race/ethnicity (proportion white, nonwhite, or Hispanic), age (eight categories), proportion "urbanized areas and clusters" as defined by the U.S. Census Bureau (of the total land area), current mining employment, and density of active mines (per square mile). All these were derived from census data except the last two, which were obtained from RAMLIS. The final fully-adjusted model (Model 1) was also evaluated within all 1283 AML and non-AML communities (Model 2). All models were evaluated for normality of residuals, homoscedasticity, linearity, and residual spatial variation (nonindependence) by examination of plots and similar diagnostic methods.

To assess whether reclamation decreased socioeconomic deprivation, a sensitivity analysis was conducted using the same modeling strategy but with AML burden variables created from reclaimed features only, adjusting for features that remained unreclaimed. Clustering and acid mine drainageimpacted streams had no analogous reclaimed status, so a total of eight AML variables were evaluated. These regressions were performed separately in the 510 communities with at least one reclaimed mine feature and in all $943 \mathrm{AML}$ communities.

\section{Results}

Of the 943 communities with AML, 433 had only abandoned mine features while 510 communities had at least one reclaimed mine feature (Table 1). There was large variation in the three community context outcomes in all three 


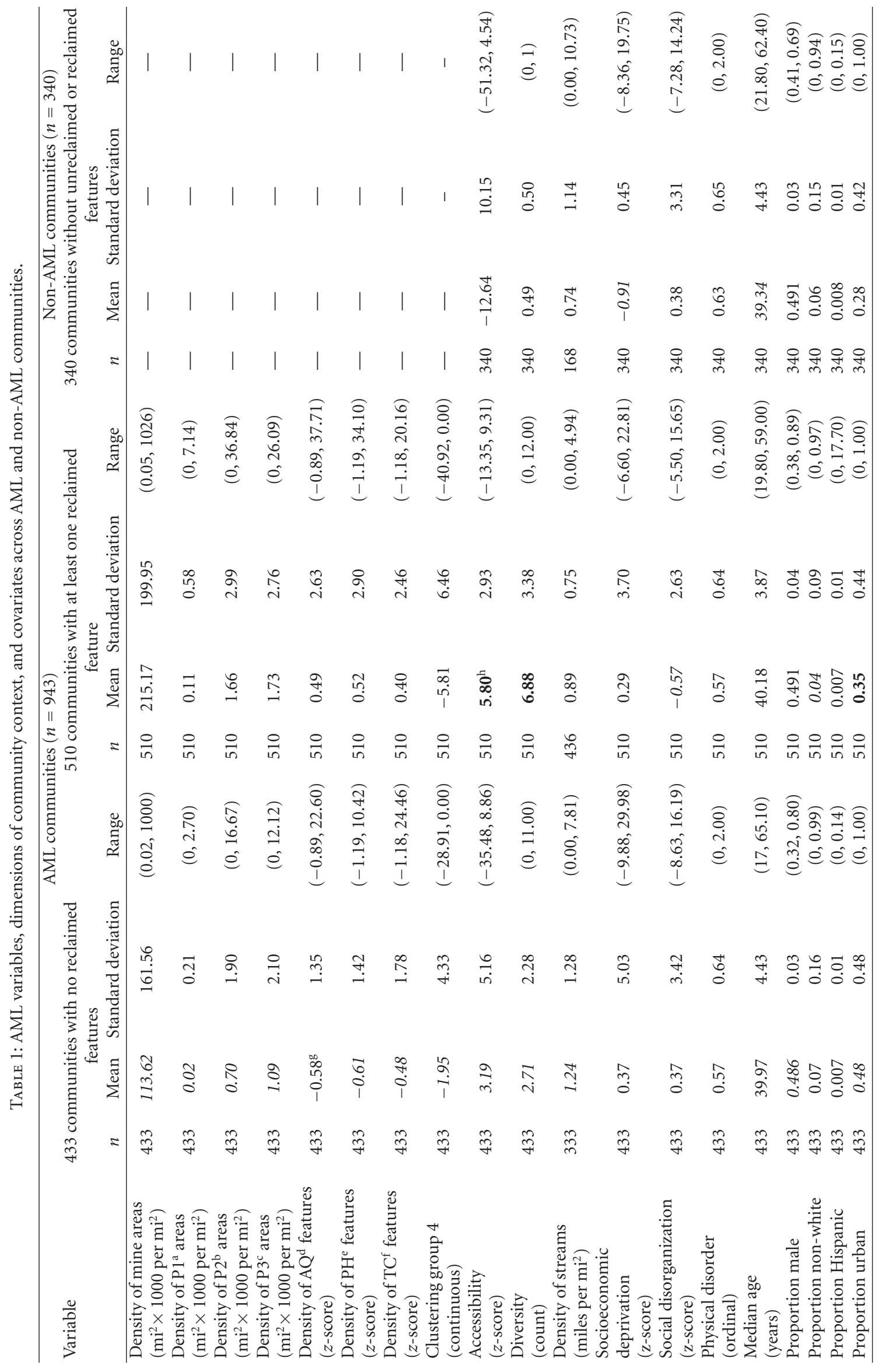




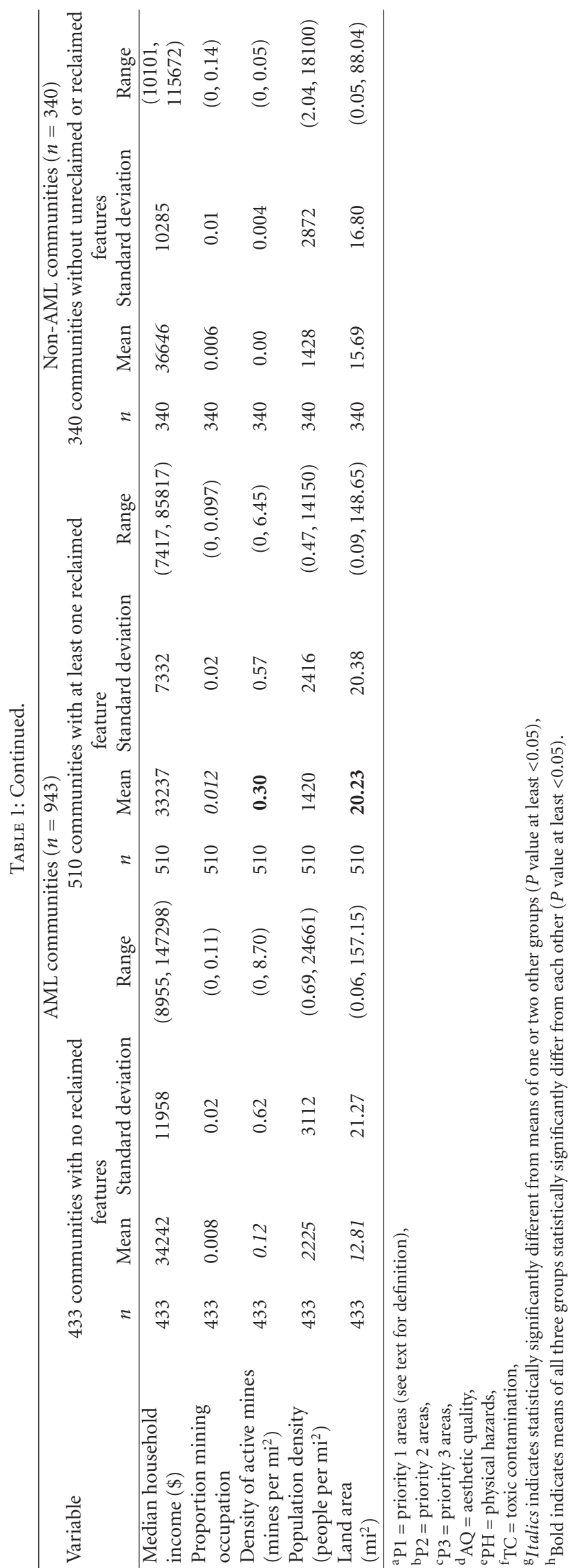


community types, and large variation in AML exposure variables in AML communities.

3.1. Socioeconomic Deprivation. With only AML communities included in the models, associations of the AML exposure variables with socioeconomic deprivation were attenuated, but remained significant, with increasing levels of covariate control. When control communities without AML were included, associations generally strengthened (Table 2, Model 2). The fully adjusted models showed several patterns of association (Table 2, Models 1 and 2). These included traditional "dose-response" (e.g., accessibility, density of acid mine drainage-impacted streams, and density of mine areas), "u-shaped" (e.g., density of physical hazards, density of toxic contamination features, and density of priority 2 areas and priority 3 areas, with tests for linear trend $P<0.05$ except for density of priority 3 areas), and threshold (e.g., density of aesthetic quality features, test for linear trend $P<0.05$ ) patterns.

3.2. Social Disorganization. In fully adjusted models, associations between AML burden and social disorganization were of two main patterns (Table 2, Models 5 and 6). Higher clustering and density of acid mine drainage-impacted streams were associated with more social disorganization. For the other AML variables, several followed the pattern of lower social disorganization with intermediate amounts of AML. Addition of control communities similarly tended to strengthen associations.

3.3. Physical Disorder. There were trends of increasing physical disorder across categories of AML exposure, but in no case were we able to reject the null hypothesis of no association (all $P>0.05$, data not shown).

3.4. Sensitivity Analysis. The analysis of reclaimed mine features showed inconsistent results across AML variables (Table 2, Models 3 and 4) but generally suggested that reclaimed features had no or weakened associations with socioeconomic deprivation. Consistent with hypotheses, for mine area density, toxic contamination density, priority 2 density, and accessibility, reclaimed features were not associated with socioeconomic deprivation. For aesthetic quality density and physical hazards density, associations of the highest quartile of each with socioeconomic deprivation were weaker when reclaimed features only were included. In contrast to hypotheses, reclaimed priority 3 feature density showed stronger associations compared with the main analysis. There was no evidence that residual spatial correlation accounted for any of the results.

\section{Discussion}

Underground voids and vertical mine shafts, unpleasant views of old abandoned structures and spoil piles, and stretches of tainted streams serve as a backdrop for many communities across Pennsylvania. This study provides the first evidence to suggest that some of the legacy of AMLs were associated with higher socioeconomic deprivation. Relations between AML features and social disorganization were more complicated, in that a moderate amount of AML was associated with lower social disorganization (i.e., better community context). Finally, AML features were not associated with physical disorder.

Because places influence individual health, it is important to understand how AML may contribute to community context, which can "get under the skin" to produce somatic responses [43]. Comprehending how uncommon exposures like AML may influence community context may allow novel insights about context in general. Growing evidence suggests that healthy communities are the product, in part, of features relevant to social functioning (i.e., perceived reputation of the area and positive sociocultural features of the community) and community material and institutional resources (i.e., quality of physical aspects of the environment, presence of healthy home, work, and recreational environments, and existence of public services available to all residents) [7]. Healthy communities, therefore, depend on a rich social fabric in combination with valuable material resources for members [44]. AML in and around communities, "problems of industrial and consequent social decay, like the parallel problem of urban slums" [45], may engender poor health outcomes via several mechanisms. The community burden of AML may modify physical activity behaviors because of aesthetics or concerns regarding exposures, a conclusion supported by stronger associations with the more perceptible aspects of AMLs. Additionally, lack of resources in communities with higher socioeconomic deprivation can limit access to health care, healthy food establishments, and recreational spaces and also promote poor health behaviors such as cigarette smoking, alcohol consumption, and decreased physical activity [20].

As with many such studies, problems arise regardin temporal ordering. It is not possible to determine whether an association between AML and degraded community context might be the result of the reverse process. However, in this case, we argue that unlike other environmental hazards like landfills, factories, or hazardous waste incinerators preferentially sited in poor communities [46], the location of mining operations is entirely exogenous to the characteristics of the communities where they are placed and are a function of geologic features alone. For this reason, the potential for reverse causation is reduced. It is possible that the presence of mine operations shaped the socioeconomic characteristics of the community prior to the closing of the mine or that the cessation of mining activity itself led to community decline. These possibilities cannot be ruled out given the lack of data on the cessation of active mining.

Another relevant question is whether communities have greater socioeconomic deprivation simply because of the collapse of the mining industry. Disentangling this possibility with the reclamation analysis was difficult because communities with at least one reclaimed feature also had the greatest burden of AML. However, several observations suggested the weight of evidence supported the conclusion that the physical remains of past coal mining activities may have been a more important contributor to degraded community contexts 


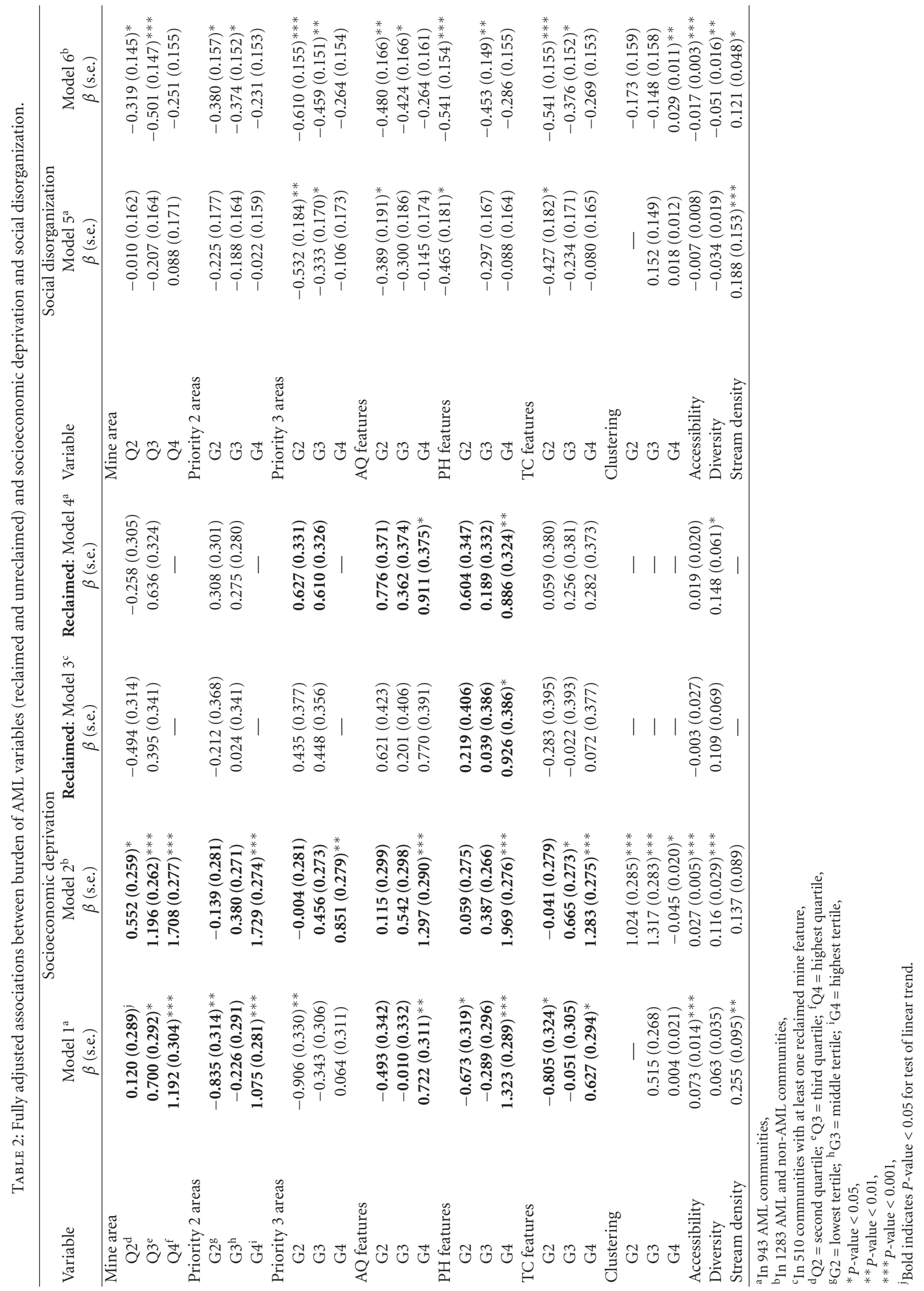


than the collapse of the mining industry. First, the density of active coal mines and current mining occupation were associated with worse socioeconomic deprivation, suggesting that ongoing mining, not its disappearance, is associated with worse community socioeconomic deprivation. Second, several AML variables that would not be considered proxies for the collapse of the mining industry were associated with worse socioeconomic deprivation. For example, the density of acid mine drainage-impacted streams in communities or the accessibility of population centers to the nearest AML features would be difficult to link with the magnitude of economic collapse following the closure of coal mines, yet these were also associated with socioeconomic deprivation.

Social disorganization is generally considered as the "inability of a community structure to realize the common value of its residents and maintain effective social controls" [37, 47]. The apparent lack of social controls in communities contributes to the unwillingness of residents to deal with signs of neighborhood disorder [48], or the lack of strong social ties to connect neighbors to one another may pave the way for crime and delinquency. There are several plausible explanations for the seemingly counterintuitive association of environmentally degraded communities with lower social disorganization. For example, having some level of AML burden in communities may help to bring residents together in their community, motivating them to work cooperatively toward a common goal $[49,50]$. In England, four studies have evaluated interactions between physical and social environments in disadvantaged neighborhoods and concluded that there remained strong feelings of mutual support and resilience [51]. People living in communities with a higher burden of AML may have greater attachment to place, richer social networks, and stronger ties to the community [50]. It is also possible that undesirable surroundings in communities may prompt people to desire to leave, but they may not have the freedom to do so, turning their attention to improving their communities, which may lead to stronger attachment [52].

The findings may have relevance to current natural gas drilling from the Marcellus shale, a process that requires considerable disruption of natural ecosystems for new road construction and drilling pads [53]. The vertical and horizontal drilling and hydraulic fracturing processes require large quantities of water and can lead to chemical, metal, and radioactive material contamination of surface and ground waters and soils [53]. Construction of miles of pipeline and compressor stations to transport the natural gas further compromises nearby air, water, and soil quality [54]. Like the legacy of AML, without careful attention, Marcellus shale activities could have impacts on communities similar to those identified herein.

Because of the substantial amount of funding provided by the 2006 Amendment to SMCRA for reclamation of coal AML and the relative lack of empirical, public health-oriented evidence for prioritizing areas for immediate reclamation, results from this study may be useful to identify communities with the greatest need for reclamation. Based on associations with community socioeconomic deprivation, the results suggest that communities in the highest quartile of mine area density or physical hazard density, for example, may be the best candidates for investing SMCRA funds for reclaiming AML if public health protection were to be, as stated in SMCRA, a primary goal.

\section{Abbreviations}

$\begin{array}{ll}\text { AML: } & \text { Abandoned mine lands } \\ \text { CT: } & \text { Census tract } \\ \text { MCD: } & \text { Minor civil division } \\ \text { RAMLIS: } & \text { Reclaimed Abandoned Mine Land Inventory } \\ & \text { System } \\ \text { SMCRA: } & \text { Surface Mining Control and Reclamation Act. }\end{array}$

\section{Acknowledgments}

This work was funded, in part, by the Johns Hopkins Education and Research Center, National Institute of Occupational Safety and Health. All authors declare they have no actual or potential competing financial interests.

\section{References}

[1] C. W. Schmidt, "Blind rush? Shale gas boom proceeds amid human health questions," Environmental Health Perspectives, vol. 119, no. 8, pp. A350-A353, 2011.

[2] U.S. Bureau of Land Management, "Abandoned Mine Lands Portal," 2011, http://www.abandonedmines.gov/index.html.

[3] R. E. Hughes and M. Hewitt, Reclaimed Abandoned Mine Land Inventory System, 2008, Shavertown, Pa, USA.

[4] U.S. Congress Editor, "Surface mining control and reclamation act title 30," USC Section 1234-1328, U.S. Government Printing Office, Washington, DC, USA, 1997.

[5] S. M. Marmot, "The social environment and health," Clinical Medicine, vol. 5, no. 3, pp. 244-248, 2005.

[6] H. Frumkin, "The Measure of Place," American Journal of Preventive Medicine, vol. 31, no. 6, pp. 530-532, 2006.

[7] A. R. Hughes, F. Gillies, A. F. Kirk, N. Mutrie, W. S. Hillis, and P. D. MacIntyre, "Exercise consultation improves short-term adherence to exercise during phase IV cardiac rehabilitation: a randomized, controlled trial," Journal of Cardiopulmonary Rehabilitation, vol. 22, no. 6, pp. 421-425, 2002.

[8] K. E. Pickett and M. Pearl, "Multilevel analyses of neighbourhood socioeconomic context and health outcomes: a critical review," Journal of Epidemiology and Community Health, vol. 55, no. 2, pp. 111-122, 2001.

[9] C. K. Nordstrom, A. V. Diez Roux, S. A. Jackson, and J. M. Gardin, "The association of personal and neighborhood socioeconomic indicators with subclinical cardiovascular disease in an elderly cohort. The cardiovascular health study," Social Science and Medicine, vol. 59, no. 10, pp. 2139-2147, 2004.

[10] C. Cubbin, K. Sundquist, H. Ahlen, S. E. Johansson, M. A. Winkleby, and J. Sundquist, "Neighborhood deprivation and cardiovascular disease risk factors: protective and harmful effects," Scandinavian Journal of Public Health, vol. 34, no. 3, pp. 228-237, 2006.

[11] J. D. Morenoff, J. S. House, B. B. Hansen, D. R. Williams, G. A. Kaplan, and H. E. Hunte, "Understanding social disparities in hypertension prevalence, awareness, treatment, and control: the role of neighborhood context," Social Science and Medicine, vol. 65, no. 9, pp. 1853-1866, 2007.

[12] T. Augustin, T. A. Glass, B. D. James, and B. S. Schwartz, "Neighbor-hood psychosocial hazards and cardiovascular dis- 
ease: the Baltimore memory study," American Journal of Public Health, vol. 98, no. 9, pp. 1664-1670, 2008.

[13] S. S. Merkin, A. V. Diez Roux, J. Coresh, L. F. Fried, S. A. Jackson, and N. R. Powe, "Individual and neighborhood socioeconomic status and progressive chronic kidney disease in an elderly population: the Cardiovascular Health study," Social Science and Medicine, vol. 65, no. 4, pp. 809-821, 2007.

[14] D. A. Shoham, S. Vupputuri, A. V. Diez Roux et al., "Kidney disease in life-course socioeconomic context: the Atherosclerosis Risk in Communities (ARIC) study," American Journal of Kidney Diseases, vol. 49, no. 2, pp. 217-226, 2007.

[15] P. B. English, M. Kharrazi, S. Davies, R. Scalf, L. Waller, and R. Neutra, "Changes in the spatial pattern of low birth weight in a southern California county: the role of individual and neighborhood level factors," Social Science and Medicine, vol. 56, no. 10, pp. 2073-2088, 2003.

[16] T. A. Farley, K. Mason, J. Rice, J. D. Habel, R. Scribner, and D. A. Cohen, "The relationship between the neighbourhood environment and adverse birth outcomes," Paediatric and Perinatal Epidemiology, vol. 20, no. 3, pp. 188-200, 2006.

[17] T. Leventhal and J. Brooks-Gunn, "Moving to opportunity: an experimental study of neighborhood effects on mental health," American Journal of Public Health, vol. 93, no. 9, pp. 15761582, 2003.

[18] M. Stafford and M. Marmot, "Neighbourhood deprivation and health: does it affect us all equally?" International Journal of Epidemiology, vol. 32, no. 3, pp. 357-366, 2003.

[19] C. F. Hybels, D. G. Blazer, C. F. Pieper et al., "Sociodemographic characteristics of the neighborhood and depressive symptoms in older adults: using multilevel modeling in geriatric psychiatry," American Journal of Geriatric Psychiatry, vol. 14, no. 6, pp. 498-506, 2006.

[20] M. Elliott, "The stress process in neighborhood context," Health and Place, vol. 6, no. 4, pp. 287-299, 2000.

[21] A. Steptoe and P. J. Feldman, "Neighborhood problems as sources of chronic stress: development of a measure of neighborhood problems, and associations with socioeconomic status and health," Annals of Behavioral Medicine, vol. 23, no. 3, pp. 177-185, 2001.

[22] M. Hendryx, "Mortality from heart, respiratory, and kidney disease in coal mining areas of Appalachia," International Archives of Occupational and Environmental Health, vol. 82, no. 2, pp. 243-249, 2009.

[23] M. Hendryx and M. M. Ahern, "Mortality in appalachian coal mining regions: the value of statistical life lost," Public Health Reports, vol. 124, no. 4, pp. 541-550, 2009.

[24] M. Hendryx, M. M. Ahern, and T. R. Nurkiewicz, "Hospitalization patterns associated with appalachian coal mining," Journal of Toxicology and Environmental Health A, vol. 70, no. 24, pp. 2064-2070, 2007.

[25] M. Hendryx, K. O’Donnell, and K. Horn, "Lung cancer mortality is elevated in coal-mining areas of Appalachia," Lung Cancer, vol. 62, no. 1, pp. 1-7, 2008.

[26] W. B. Neser, H. A. Tyroler, and J. C. Cassel, "Social disorganization and stroke mortality in the black population of North Carolina," American Journal of Epidemiology, vol. 93, no. 3, pp. 166-175, 1971.

[27] V. Carstairs, "Deprivation indices: their interpretation and use in relation to health," Journal of Epidemiology and Community Health, vol. 49, supplement 2, pp. S3-S8, 1995.

[28] M. Malmstrom, J. Sundquist, and S. E. Johansson, "Neighborhood environment and self-reported health status: a multilevel analysis," American Journal of Public Health, vol. 89, no. 8, pp. 1181-1186, 1999.
[29] D. Cohen, S. Spear, R. Scribner, P. Kissinger, K. Mason, and J. Wildgen, "Broken windows' and the risk of gonorrhea," American Journal of Public Health, vol. 90, no. 2, pp. 230-236, 2000.

[30] C. E. Ross and J. Mirowsky, "Neighborhood disadvantage, disorder, and health," Journal of Health and Social Behavior, vol. 42, no. 3, pp. 258-276, 2001.

[31] M. K. Stjarne, J. Fritzell, A. P. de Leon, and J. Hallqvist, "Neighborhood socioeconomic context, individual income and myocardial infarction," Epidemiology, vol. 17, no. 1, pp. 14-23, 2006.

[32] J. P. Stimpson, A. C. Nash, H. Ju, and K. Eschbach, "Neighborhood deprivation is associated with lower levels of serum carotenoids among adults participating in the Third National Health and Nutrition Examination Survey," Journal of the American Dietetic Association, vol. 107, no. 11, pp. 1895-1902, 2007.

[33] R. C. Brownson, C. M. Hoehner, K. Day, A. Forsyth, and J. F. Sallis, "Measuring the built environment for physical activity: state of the science," American Journal of Preventive Medicine, vol. 36, supplement 4, pp. S99-S123.e12, 2009.

[34] J. Feng, T. A. Glass, F. C. Curriero, W. F. Stewart, and B. S. Schwartz, "The built environment and obesity: a systematic review of the epidemiologic evidence," Health and Place, vol. 16, no. 2, pp. 175-190, 2010.

[35] R. Cervero and K. Kockelman, "Travel demand and the 3Ds: density, diversity, and design," Transportation Research D, vol. 2, no. 3, pp. 199-219, 1997.

[36] P. Townsend, "Deprivation," Journal of Social Policy, vol. 16, no. 2, pp. 125-146, 1987.

[37] R. J. Sampson and W. B. Groves, "Community structure and crime: testing social-disorganization theory," American Journal of Sociology, vol. 94, no. 4, pp. 774-802, 1989.

[38] I. H. Yen and S. L. Syme, "The social environment and health: a discussion of the epidemiologic literature," Annual Review of Public Health, vol. 20, pp. 287-308, 1999.

[39] D. W. Osgood and J. M. Chambers, "Social disorganization outside the metropolis: an analysis of rural youth violence," Criminology, vol. 38, no. 1, pp. 81-114, 2000.

[40] I. H. Yen, Y. L. Michael, and L. Perdue, "Neighborhood environment in studies of health of older adults: a systematic review," American Journal of Preventive Medicine, vol. 37, no. 5, pp. 455-463, 2009.

[41] R. G. Netemeyer, W. O. Bearden, and S. Sharma, Scaling Procedures: Issues and Applications, Sage Publications, Thousand Oaks, Calif, USA, 2003.

[42] S. Selvin, I. J. Schulman, and D. W. Merrill, "Interpoint squared distance as a measure of spatial clustering," Social Science and Medicine, vol. 36, no. 8, pp. 1011-1016, 1993.

[43] S. E. Taylor, R. L. Repetti, and T. Seeman, "Health psychology: what is an unhealthy environment and how does it get under the skin?" Annual Review of Psychology, vol. 48, pp. 411-447, 1997.

[44] S. Macintyre and A. Ellaway, "Neighborhoods and health: an overview," in Neighborhoods and Health, I. Kawachi and L. F. Berkman, Eds., pp. 20-42, Oxford University Press, New York, NY, USA, 2003.

[45] J. T. Hart, “The health of coal mining communities.," Journal of the Royal College of General Practitioners, vol. 21, no. 110, pp. 517-528, 1971.

[46] M. R. I. Soliman, C. T. Derosa, H. W. Mielke, and K. Bota, "Hazardous wastes, hazardous materials and environmental health inequity," Toxicology and Industrial Health, vol. 9, no. 5, pp. 901-912, 1993. 
[47] S. Saegert and G. Winkel, "Crime, social capital, and community participation," American Journal of Community Psychology, vol. 34, no. 3-4, pp. 219-233, 2004.

[48] D. D. Perkins and R. B. Taylor, "Ecological assessments of community disorder: their relationship to fear of crime and theoretical implications," American Journal of Community Psychology, vol. 24, no. 1, pp. 63-107, 1996.

[49] I. Kawachi, B. P. Kennedy, and R. G. Wilkinson, "Crime: social disorganization and relative deprivation," Social Science and Medicine, vol. 48, no. 6, pp. 719-731, 1999.

[50] R. Forrest and A. Kearns, "Social cohesion, social capital and the neighbourhood," Urban Studies, vol. 38, no. 12, pp. 2125$2143,2001$.

[51] R. Forrest and A. Kearns, Social Cohesion and Urban Inclusion for Disadvantaged Neighbourhoods. Foundations, Joseph Roundtree Foundation, York, UK, 1999.

[52] R. B. Taylor, "Neighborhood responses to disorder and local attachments: the systemic model of attachment, social disorganization, and neighborhood use value," Sociological Forum, vol. 11, no. 1, pp. 41-74, 1996.

[53] Natural Resources Defense Council, "Protecting New Yorkers' health and the environment by regulating drilling in the Marcellus Shale," 2011, http://www.nrdc.org/land/files/marcellus. pdf.

[54] J. Burnett, "Health issues follow natural gas drilling in Texas," 2011, http://www.npr.org/templates/story/story.php?storyId= 120043996. 


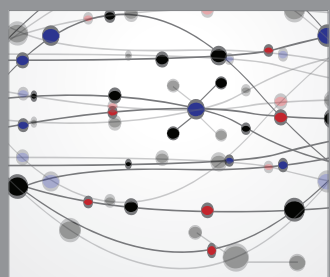

The Scientific World Journal
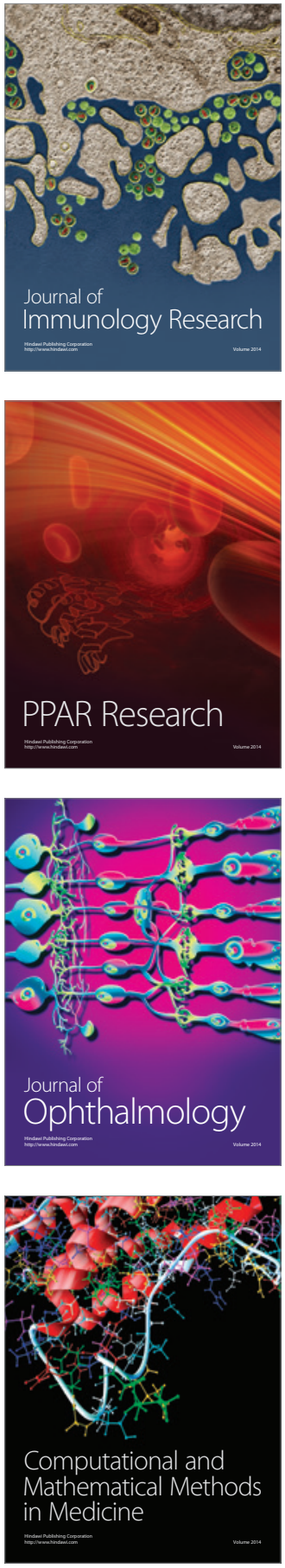

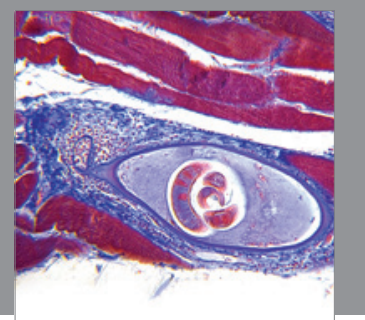

Gastroenterology

Research and Practice
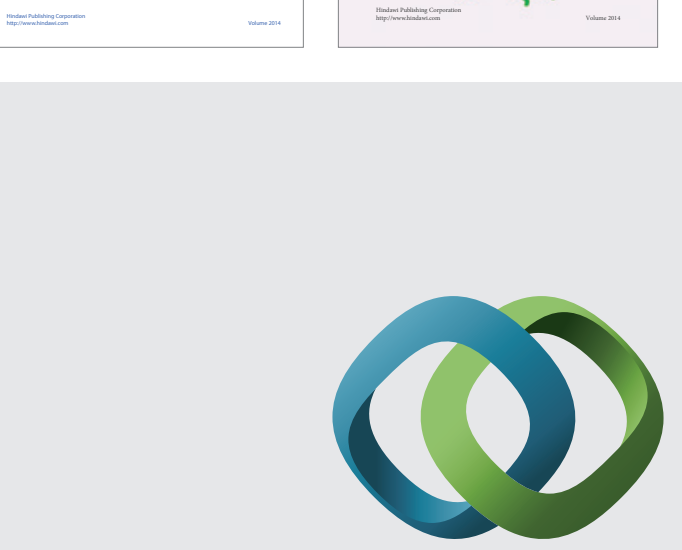

\section{Hindawi}

Submit your manuscripts at

http://www.hindawi.com
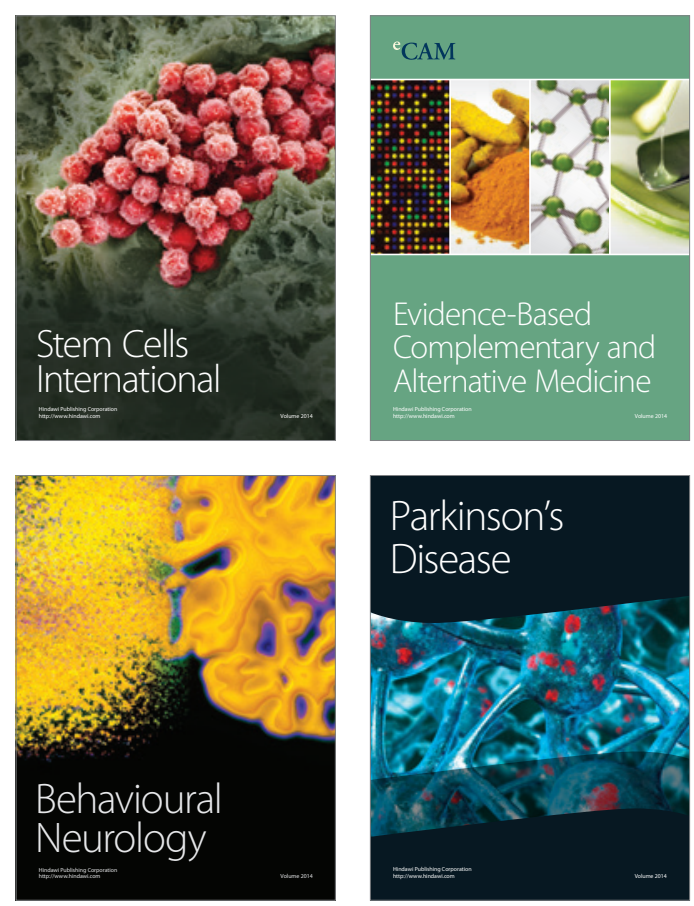

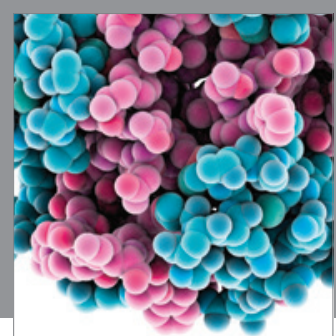

Journal of
Diabetes Research

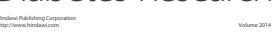

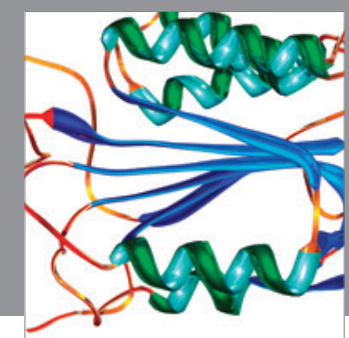

Disease Markers
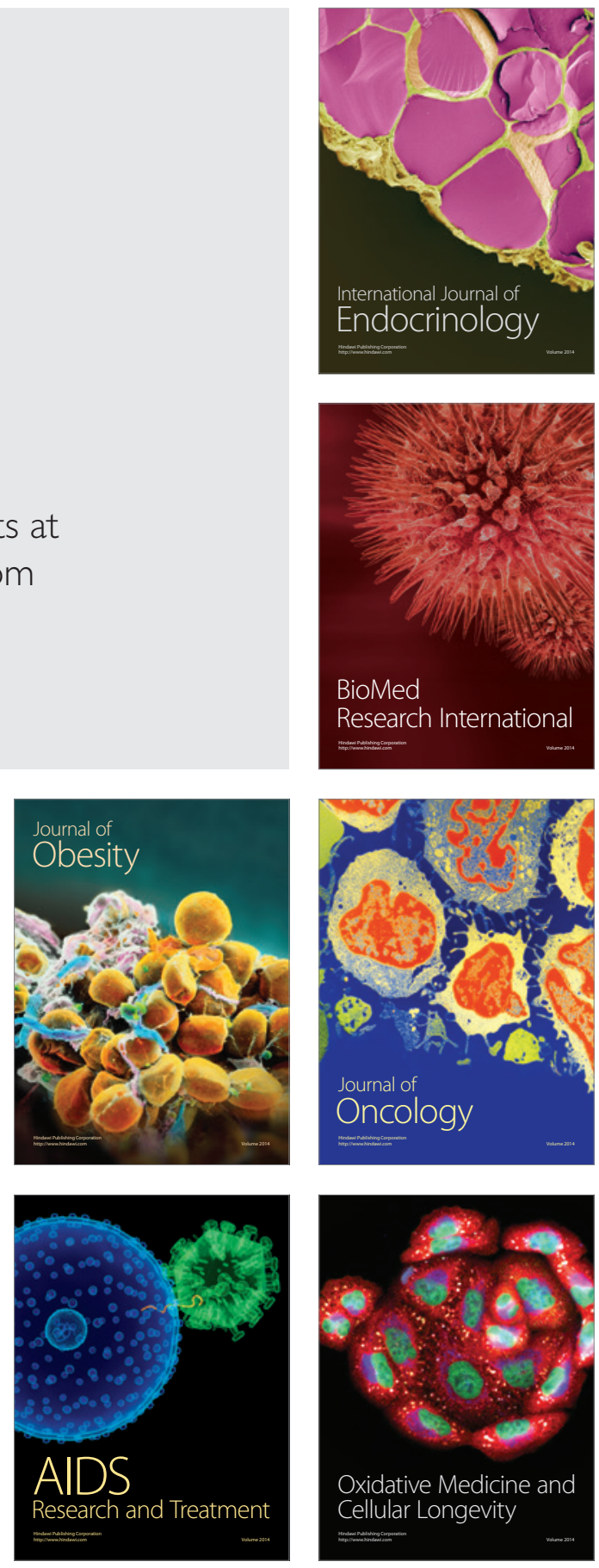